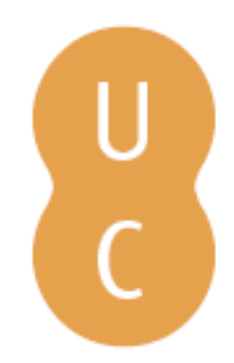

\title{
pompalina
}

\section{Cenografias dissonantes: da "discrição" e da "honnêteté" no imaginário barroco}

\author{
Autor(es): $\quad$ Anacleto, Marta Teixeira \\ Publicado por: Imprensa da Universidade de Coimbra; Ediciones Universidad \\ URL \\ persistente: URI:http://hdl.handle.net/10316.2/31505 \\ DOI: $\quad$ DOI:http://dx.doi.org/10.14195/978-989-26-0245-5_3 \\ Accessed : $\quad$ 26-Apr-2023 13:54:27
}

A navegação consulta e descarregamento dos títulos inseridos nas Bibliotecas Digitais UC Digitalis, UC Pombalina e UC Impactum, pressupõem a aceitação plena e sem reservas dos Termos e Condições de Uso destas Bibliotecas Digitais, disponíveis em https://digitalis.uc.pt/pt-pt/termos.

Conforme exposto nos referidos Termos e Condições de Uso, o descarregamento de títulos de acesso restrito requer uma licença válida de autorização devendo o utilizador aceder ao(s) documento(s) a partir de um endereço de IP da instituição detentora da supramencionada licença.

Ao utilizador é apenas permitido o descarregamento para uso pessoal, pelo que o emprego do(s) título(s) descarregado(s) para outro fim, designadamente comercial, carece de autorização do respetivo autor ou editor da obra.

Na medida em que todas as obras da UC Digitalis se encontram protegidas pelo Código do Direito de Autor e Direitos Conexos e demais legislação aplicável, toda a cópia, parcial ou total, deste documento, nos casos em que é legalmente admitida, deverá conter ou fazer-se acompanhar por este aviso.

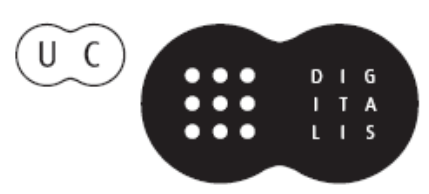


Marta Teixeira Anacleto

Sara Augusto

Zulmira Santos

Coordenação

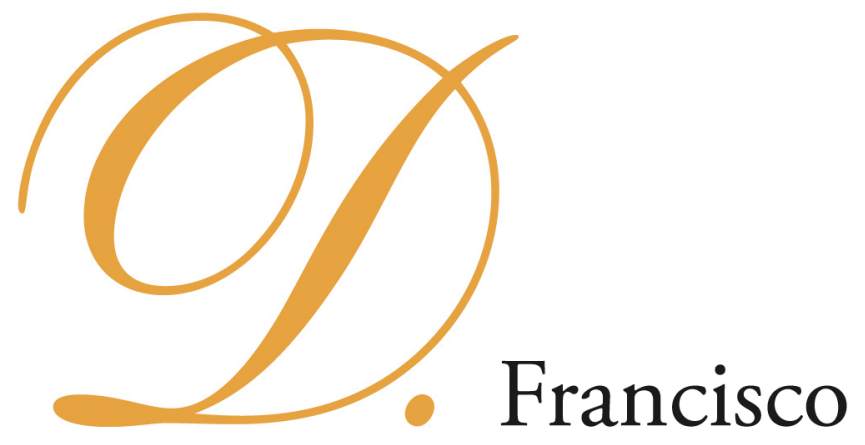

Manuel de Melo e o

Barroco Peninsular 


\title{
EDIĈ̣̃O
}

Imprensa da Universidade de Coimbra Ediciones Universidad Salamanca

\section{COORDENAÇÃo EDITORIAL}

Imprensa da Universidade de Coimbra

URL: http://www.uc.pt/imprensa_uc

Vendas online: http://www.livrariadaimprensa.com

\section{CONCEPÇÃO GRÁFICA}

António Barros

\section{REVISÃO TEXTO}

Sara Augusto

\author{
Pré-Impressão, Impressão e ACABamento \\ www.artipol.net
}

\section{IS B N}

978-989-26-0044-4 (Portugal)

978-84-7800-194-1 (Espanha)

DEPósito LEGAL

$311680 / 10$

OBRA PUBlicada COM O APOIO DE:

FCT Fundação para a Ciência e a Tecnologia

MINISTÉRIO DA CIÊNCIA, TECNOLOCIA E ENSINO SUPERIOR Portugal

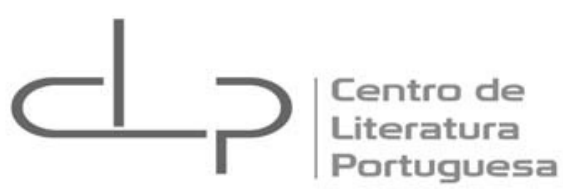

A presente publicação insere-se no Grupo "Poéticas" (coordenação de Marta Teixeira Anacleto) do Centro de Literatura Portuguesa, Unidade de I\&D financiada pela Fundação para a Ciência e a Tecnologia, ao abrigo do Programa Operacional Ciência e Inovação 2010.

(C) Agosto 2010

IMPRENSA DA UNIVERSIDADE DE COIMBRA

EDICIONES UNIVERSIDAD DE SALAMANCA 
Marta Teixeira Anacleto

Sara Augusto

Zulmira Santos

Coordenação

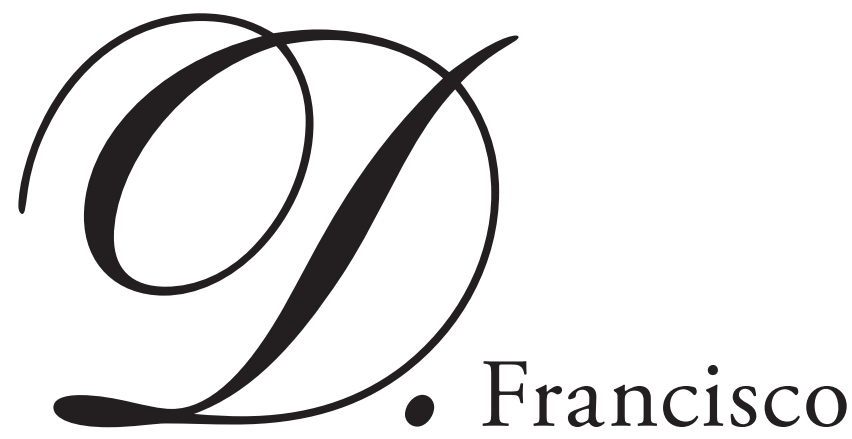

Manuel de Melo e o Barroco Peninsular

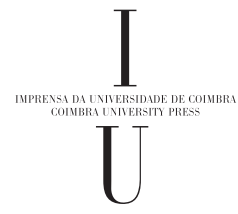


PARTE I

FORMAS E IMAGINÁRIO(s) DO BARROCO 


\author{
Marta Teixeira Anacleto \\ Centro de Literatura Portuguesa \\ Universidade de Coimbra
}

\title{
CENOGRAFIAS DISSONANTES: DA «DISCRIÇĀO»E DA «HONNÊTETÉ» NO IMAGINÁRIO BARROCO
}

A primeira parte do título desta reflexão - «cenografias dissonantes» - aplicada a duas categorias éticas e estéticas que participam da construção do imaginário barroco peninsular e francês (compreendendo-se o «barroco» francês numa dimensão modal que se entende ultrapassar a cronológica), justifica-se, em boa parte, pelo facto de a enunciação dessas categorias ser «representada» ou colocada em representação nos dois contextos, num cruzamento constante entre a escrita e a sua figuraçáo social. É, pois, do conceito de «representação», abrangendo a dimensão antropológica e cultural da «discrição» e da "honnêteté», de que se parte, sem poder (ou querer) ignorar que o jogo cénico-literário dos comportamentos, no barroco peninsular e, em certa medida, no barroco francês, não se fixa apenas, como sublinha Rodriguez de la Flor, na ostentaçâo e na exuberância dos conteúdos e formas, mas também (e ao mesmo tempo), na sua ocultação e dissimulação, sob o olhar do eu/escritor e do outro de si (o «eu político») ${ }^{1}$. É, ainda, associando, em amplificatio, os significados da «representação» desses dois paradigmas comportamentais às figuraçôes da alegoria e do theatrum mundi no imaginário barroco da Contra-Reforma, no imaginário social de uma palavra colectiva, que parece ser possível equacionar dissonâncias (que forçosamente englobam paralelismos) no domínio da antropologia moral na qual se inscrevem a «discrição» e a «honnêteté» e a subsequente expressão estética da sociabilidade cortesã que desde Castiglione (1528), Giovani della Casa (1558), Stefano Guazzo (1574), os escritores tentam legitimar ou "fabricar».

O universo de olhares interiores e exteriores que emana da obra multifacetada e cosmopolita de D. Francisco Manuel de $\mathrm{Melo}^{2}$, enunciado nas primeiras páginas da Carta

${ }^{1} \mathrm{O}$ autor desenvolve a ideia de que a intimidade e o segredo invadem o campo do imaginário e da psicologia do Barroco, existindo uma dialéctica complexa entre o "eu interior» e o "eu político», espelhado na Corte como locus impossível e fatal (ver Rodriguez de la Flor, Fernando, Pasiones frias. Secreto y disimulación en el Barroco hispano. Madrid: Marcial Pons Historia, 2005, p. 15).

${ }^{2}$ Ver, a propósito da obra multifacetada de D. Francisco Manuel de Melo, o estudo panorâmico que Maria Lucília Gonçalves Pires lhe consagra em obra publicada em 2002, começando justamente por afirmar: «D. Francisco Manuel de Melo é uma das figuras que assumem maior relevo no panorama cultural português do século XVII: pela multiplicidade e diversidade da obra que nos legou; pela forma como soube reflectir, nos seus diversos aspectos, o 
de Guia de Casados - «Criei-me em Cortes; andei por esse mundo; atentava para as cousas; guardava-as na memória. Vi, li. Ouvi.»³ -, a "exquisita variedade» dos seus textos dando lugar a uma percepçáo multímoda (sensorial) do mundo cultural, político e social em que viveu, a memória que dele foi construindo no isolamento - «A memória está na memória», dirá a personagem do Autor no Hospital das Letras ${ }^{4}$-, será simultaneamente o alibi teórico deste estudo, para delimitar, em esboço e num registo de mera hipótese de trabalho, as diferentes cenografias construídas pelo confronto dos dois modelos de humanidade associados à "discrição» e à "honnêteté».

De facto, não só o arquitexto meliano é construído sobre um confronto e cruzamento de diferentes códigos poéticos que se corporizam na figura do polígrafo interiorizada especularmente pelo Autor do Hospital das Letras - «gastando tantas horas em escrever, não gastei ũa só em me arrepender de ter escrito tanto" ${ }^{5}$-, como também os diversos actores (autor e personagens dramatizadas) dos Tratados, Apólogos, Obras Métricas (no sentido amplo), textos dramáticos, historiográficos e epistolares, corporizam, na escrita, modelos sociais que relativizam os significados a priori crípticos do «discreto», para que o seu confronto como outros modelos comportamentais, como o do "honnête homme», se torne legítimo no contexto do imaginário e na estética barrocos ${ }^{6}$. Será, por conseguinte, nesta duplicidade heurística (a escrita e o conceito), que me irei situar relativamente ao prolixo universo da obra de D. Francisco Manuel, entendido como tal, pelo autor barroco (ou do barroco), no final da Carta de Guia de Casados - «eu de meu natural sou miúdo e proluxo; o estar só e a melancolia, que de si é cuidadosa, me fizeram armar tâo largas redes para colher dentro delas todos os casos e todos os avisos» ${ }^{7}$.

$\mathrm{O}$ "grau zero» das cenografias a descrever situa-se nessa contingência inultrapassável e afim aos dois contextos - peninsular e francês - que é a «fragilidade» (comecemos por utilizar esta designação) e o carácter difuso dos próprios conceitos de "discrição» e "honnêteté» no século XVII. Dessa fragilidade resulta, em boa medida, a tentação da sua sobreposição ou cruzamento que levou a crítica, durante algumas décadas, a discorrer sobre duas formas similares de representação de um modelo social - o do cortesão discreto e o do «honnête homme» em Portugal, Espanha e França ${ }^{8}$. O espectro de lexemas metonímicos da

universo cultural, social e político em que viveu; e sobretudo, pela dimensão estética que a sua obra geralmente apresenta, nos vários níveis estilísticos em que moldou a sua escrita.» («D. Francisco Manuel de Melo», in História da Literatura Portuguesa. Da Época Barroca ao Pré-romantismo. Lisboa: Publicaçōes Alfa, 2002, p. 101).

${ }^{3}$ D. Francisco Manuel de Melo, Carta de Guia de Casados (ed. de Pedro Serra). Coimbra: Angelus Novus, 1996, p. 91.

${ }^{4}$ D. Francisco Manuel de Melo, Apólogos Dialogais, vol. II - O Escritório Avarento. O Hospital das Letras (ed. de Pedro Serra). Coimbra: Angelus Novus, 1999, p. 107.

${ }^{5}$ Ibidem, p. 108.

${ }^{6}$ Náo existindo uma bibliografia muito sistemática sobre esse confronto, importa, no entanto, reter a importante reflexão-síntese que ao assunto consagrou actualmente Paulo da Silva Pereira (D. Francisco Manuel de Melo e o modelo do 'cortesão prudente e discreto' na cultura Barroca Peninsular. Coimbra: Faculdade de Letras da Universidade de Coimbra, 2007 (Dissertação de Doutoramento).

${ }^{7}$ D. Francisco Manuel de Melo, op. cit., 1996, p. 190.

${ }^{8}$ Ver, entre outros, Emmanuel Bury, Littérature et politesse. L invention de l'honnête homme (1580-1750). Paris: P.U.F., 1996; Jean-Pierre Dens, L'Honnête homme et la critique du goût (Esthétique et société au XVIIe siècle). Lexington-Kentucky: French Forum Publishers, 1981; Maurice Magendie, La politesse mondaine et les 
categoria da «discrição" que, à primeira vista, poderemos encontrar nos textos de Gracián, Rodrigues Lobo, D. Francisco Manuel (para náo aludir a outros de natureza similar) prudência, cortesania, temperança, modéstia, honra, galantaria, engenho, agudeza, gosto apontam para um elitismo ético e cultural que faz parte de um todo e que define um paradigma - o do perfeito cortesão -, um modelo de "savoir-vivre» que encontra paralelo, numa primeira leitura, em paradigmas de comportamento de Corte divulgados, em França, no século XVII, pelos tratados de Nicolas Faret, do Chevalier de Méré, de Antoine de Courtin, Guéret e, ainda, Sorel ou Mlle de Scudéry ${ }^{9}$. Os jogos conceptuais a partir dos quais se organiza o ideal de sociabilidade cortesão nos textos destes autores (englobando a Corte ou as Academias privadas como a "chambre bleue» de Mme de Rambouillet ${ }^{10}$ ) encontram-se submetidos à uma indefiniçáo estratégica de fronteiras que permite a conivência aparentemente sinonímica de conceitos social e literariamente codificados, como o de "gentillesse», "honnêteté», «modestie», "coutoisie», «honneur», "civilité», "galanterie», que fazem parte de uma «littérature de la civilité» (de acordo com Emmanuel Bury ${ }^{11}$ ).

É, em primeira instância, o ethos social e moral que determina o diálogo entre os modelos de comportamento peninsular e francês num imaginário barroco (prolongado na «época clássica» francesa) que se centraliza na exibição da dissimulação, sem que o oximoro seja completamente revelado, e na "vertu du dehors» realçada por La Bruyère, patente na construção alegórica da persona ${ }^{12}$. Porém, a polifonia das culturas, dos textos, das identidades autorais justifica que se ultrapasse esta possível colagem conceptual da biblioteca antropológica do discreto e da biblioteca antropológica do "honnête homme»: o funcionamento alegórico da Bibliothèque Françoise de Sorel, onde se avalia os «bons» e as «maus livros» de uma paideia mundana náo coincide com a alegoria pessoal do Hospital das Letras.

Como mostra Paulo da Silva Pereira «é mais relevante o que os distingue [o «discreto» e o "honnête homme»] do que eventualmente o que possa uni-los, por não ser a mesma base antropológica de que partem, nem os fins que perseguem ${ }^{13}$. A Magendie, Bury e

théories de l'honnêteté. Genève: Slatkine, 1970; Alain Montandon (dir), Pour une histoire des traités de savoir-vivre en Europe. Clermont-Ferrant: APFLS de Clermont-Ferrand, 1995.

${ }^{9}$ Ver a síntese realizada a propósito das fontes da honnêtetê por Emmanuel Bury, «A la recherche d'une synthèse française de la civilité: l'honnêteté et ses sources», in Alain Montandon (dir.), op. cit., 1995, pp. 179-214.

${ }^{10}$ Sobre o lugar simbólico ocupado pelo "Hôtel de Rambouillet» na cultura francesa de Corte do século XVII e as suas implicações na formação de modelos de comportamentos, deverá ser consultada a obra de referência de René Bray, La préciosité et les précieux de Thibaut de Champagne à Jean Giradoux. Paris: A. Nizet, 1960. Será, ainda, pertinente observar a reflexão de Fumaroli dedicada a Mme de Rambouillet, que a vê como "donna di palazzo» de Castiglione e à sua "chambre bleue» como uma "chambre rhétorique», em «Rhétorique et société en Europe (XVIe-XVIIe siècles) - La République des lettres (III). Conversation et sociétés de conversation à Paris au XVIIIe siècle», in Annuaire du Collège de France, 90e année, 1989-1990, pp. 461-478.

${ }^{11}$ Ver E. Bury, op. cit., 1996, p. 67.

${ }^{12}$ L. Van Delft aponta, em estudo sobre a dissimulação honnête, a posição de La Bruyère, de acordo com o qual a "vertu du dehors» define o «esprit de politesse», em «La notion de 'dissimulation honnête' dans la culture classique», in Bernard Yon (dir.), Prémices et Floraison de l'Âge classique. Mélanges en l'honneur de Jean Jehasse. Saint-Étienne: Publications de l'Université de Saint-Etienne, 1995, p. 259.

${ }^{13}$ Paulo da Silva Pereira, op. cit., 2007, p. 88. A mesma posição é assumida por Mercedes Blanco, quando acentua que a arte do "honnête homme» tem como objectivo a sedução e não a dominação que procura o discreto («Les discours sur le savoir-vivre dans l'Espagne du Siècle d'Or», in Montandon, Alain (dir), op. cit., 1995, p. 171). 
Alain Montandon, citados pelo autor e já referidos nesta reflexão, aduziria os trabalhos recentes de Delphine Denis - Le Parnasse galant ${ }^{14}$ - e Alain Viala - La France Galante ${ }^{15}$ que vieram reforçar esta dissonância (não rejeitando porém a imbricação conceptual) sem, no entanto a referir, confinados que estão os autores ao imaginário francês. Mas a "galanterie» vista como amplificatio da "honnêteté» será porventura a marca social e estética mais visível dessa diferença antropológica que separa o discreto do «honnête homme» e que me leva a avaliar, para ultrapassar, agora, este prévio «grau zero» de representação, a sua ancoragem em modelos de cortesania dramatizados de forma diferenciada em imaginários com uma semântica contígua (o peninsular e o francês).

A cenografia seguinte - a que sucede a esse "grau zero» que referia - será, pois, aquela que descreve a relaçáo do "discreto» e do "honnête homme» com estigmas de interioridade e de exterioridade ${ }^{16}$, com o olhar de si próprio e o olhar politicamente insistente do outro que conduz a um registo de dissimulação ou ilusão, ora denunciado (a Fonte Velha em $A$ Visita das Fontes), ora integrado, como artifício, de forma céptica (Philinte de Le Misanthrope, de Molière). Assim, a visão antropológica marcadamente barroca do homem inseguro que procura na tipificaçáo de comportamentos - ou seja, na sua relação com o exterior - motivo de estabilidade, está na base de uma relação estudada com a Corte que, no caso peninsular, se manifesta na prudência civil, constructo artificioso associado a um fundo ético, a uma virtude socializada. A máscara do "discreto» de Gracián ${ }^{17}$ pressupóe, com efeito, a ostentação e contenção, a estilização ou racionalidade dos gestos, formas de tratamento, agudeza, engenho, gosto e elegância na conversação. Obedecendo ao mesmo modelo, desta vez integrado na nostalgia de uma Corte antiga, Rodrigues Lobo aproxima o cortesão discreto do mito da urbanidade, no Diálogo XII da Côrte na Aldeia, quando ao engenho, agudeza, entendimento vivo, prudência e razão, acrescenta «o aviso no falar, a discrição no escrever, a brandura no conversar, a polícia no vestir, a graça no parecer, a cortesania no tratar, a liberalidade no despender, o esforço no pelejar, a larguesa no jogar, a humildade no servir e a pontualidade no merecer ${ }^{18}$.

Num mesmo universo de máscaras sociais emergentes numa sociedade em crise, D. Francisco Manuel defende o «honrado casamento», a «moderação», no amor na Carta de Guia de Casados $^{19}$, alargando depois essa "Filosofia Económica» aos diálogos morais e alegóricos que legitimam a figuração de uma espécie de retrato invertido do discreto,

${ }^{14}$ Delphine Denis, Le Parnasse Galant. Institution d'une catégorie littéraire au XVII siècle. Paris: Honoré Champion, 2001.

${ }^{15}$ Alain Viala, La France galante. Paris: PUF, 2008.

${ }^{16}$ Sobre o conceito de «interioridade» e «exterioridade» e a sua relação com os conceitos de «artifício» e «ilusão», ver Bernard Beugnot, La Mémoire du texte. Essais de poétique classique. Paris: Honoré Champion Editeur, 1994.

${ }^{17}$ A reflexão levada a cabo por Rodriguez de la Flor sobre a obra de Gracián e a ética da dissimulação, a construção do homo artificialis, a alegoria dessa era melancólica, torna-se, no contexto desta reflexão, fundamental (op. cit., 2005; idem, Era melancólica. Figuras del imaginário barroco. Palma de Mallorca: José J. de Olańeta Editor - Edicions UIB, 2007).

${ }^{18}$ Francisco Rodrigues Lobo, Côrte na aldeia e noites de inverno. Lisboa: Livraria Sá da Costa Editora, 1945, p. 114.

${ }^{19}$ D. Francisco Manuel de Melo, op. cit., 1996, pp. 92, 95. 
quando o Relógio da Cidade traça, perante o Relógio da Aldeia, as mentiras dos cortesãos, a sua hipocrisia e superstição ${ }^{20}$, ou quando a "cortesã palavra» ${ }^{21}$, a que alude o Soldado de $A$ Visita das Fontes, a prudência no vestir referida pela Fonte Velha ${ }^{22}$, são confrontadas com a dissimulação que Apolo vê na Corte, cenário de um percurso de aprendizagem da discrição e prudência em que a Fonte Nova é iniciada sob os espectro da nostalgia do passado e do desvario do presente (o mundo como «feira dilatada» ${ }^{23}$ ).

Ainda, a oportunidade de utilizar o artifício da meta-reflexividade leva a que o polígrafo inclua, na imago do "discreto», uma pedagogia de leituras (no Hospital das Letras) que o modela no bom gosto e que, no caso dos príncipes, como afirma Lípsio, permite, pelo conhecimento dos tratados políticos, que «salve $(\mathrm{m})$ as suas almas» e os ajude a governar com «igualdade, arte, modéstia e inteireza»" ${ }^{24}$. Esta apropriação alegórica da imagem de si próprio (o "Autor») e da imagem do ideal cortesão que torna, em certa medida, a escrita de D. Francisco Manuel uma proposta de síntese desse modelo de comportamento, mostra como a definição do «discreto» se centraliza num culto da interioridade típico do imaginário barroco peninsular, exacerbando a virtude da prudência no espaço fechado e circular do Terreiro do Paço (em $A$ Visita das Fontes), no espaço de uma Corte «doméstica» ou, como prefere Pedro Serra, num "teatro íntimo» ${ }^{25}$ forçosamente melancólico.

Ora a ética da dissimulaçáo em que se filia esta faceta privada da prudência civil e da discrição peninsulares pode, em primeira instância, numa aproximação da perspectiva ética ao modelo social e literário, coincidir com as qualidades do «honnête homme» de Nicolas Faret (1630), «courtisan vertueux» ${ }^{26}$ submetido a uma arte do parecer intrínseca à interioridade reinventada para saber viver na «société de cour», espaço do jogo de olhares onde se pretende, também com nostalgia, recuperar o brilho dos Valois: a cultura das aparências exprime-se, em Faret, desde o «Tableau de Cour» inicial à descrição «De la Vie de la Cour», «De l'entretient du Prince», «De la conversation des grands» ou «De la conversation des femmes» ${ }^{27}$ ou, ainda, à análise de uma retórica submetida a normas da

${ }^{20}$ D. Francisco Manuel de Melo, Apólogos Dialogais, vol. I - Os Relógios Falantes. A Visita das Fontes (ed. de Pedro Serra). Coimbra: Angelus Novus, 1998, pp. 7, 8, 18.

${ }^{21}$ Ibidem, p. 42.

22 Ibidem, p. 84.

${ }^{23}$ Ibidem, p. 55. E ainda: «[Fonte Velha] Não vos fieis, amiga, de frontespícios! Casas vereis, por essa Corte, todas janelas, e dentro pouco agasalho" (ibidem, p. 50).

${ }^{24} \mathrm{O}$ discurso de Lípsio apoia-se justamente em significativas reflexôes dispersas sobre a leitura dos príncipes: "que coisa mais própria sua que dar aos Reis - como aos homens mais importantes do mundo - os documentos por donde, governando-se bem, náo só salvem suas almas, mas ainda, por virtude da paz, justiça e temperança, [que] incumbe aos Reis, disponham como também se salvem aqueles a que governam e senhoream»; «nos púlpitos se trata da instrução dos Príncepes e ainda a sua emenda com tal igualdade, arte, modéstia e inteireza como se o próprio púlpito fosse o mesmo confessionário (...)» (D. Francisco Manuel de Melo, op. cit., 1999, pp. 116, 117).

${ }^{25}$ No prefácio ao vol. II dos Apólogos, o autor refere que todos os espaços são aí visões do mundo expressas em modo espacial, teatros íntimos de uma escrita alegórica e moralizante (ibidem, «Prefácio», p. XII).

${ }^{26}$ Maurice Magendie, op. cit., 1970, p. 369.

${ }^{27}$ Ver «Tableau de la Cour - De la profession du gentil-homme; De la grace naturelle»; «De la Vie de la Cour Contre les courtisans avares et ambitieux; De l'Estime et comme elle se doit acquérir»; "De la conversation des grands - De la courtoisie des Grands en nostre Cour et de l'Estat qu'ils font des honnestes gens; Des connaissances 
cortesia (o tom de voz, o gesto, o vestuário). Seja como for, este primeiro esforço de síntese teórica não pode separar-se da ambivalência de um século que, em França, se partilha entre a interioridade e o espectáculo, o retiro íntimo e a vertigem do mundano ${ }^{28}$, razão pela qual o texto de Faret apresenta já signos exteriores (o percurso para atingir a honra e para fazer carreira no espaço aúlico) que anunciam o «honnête homme» mundano das Conversations (1668) e dos Discours (1677) do Chevalier de Méré29. A abertura à exterioridade e à universalização do indivíduo, sob a influência de Montaigne, introduz, assim, a dissonância relativamente à interioridade do «discreto», formalizada num programa de educação mundana ou "courtoisie mondaine», onde a faceta estética - o gosto, a graça, o "agrément», o «je-ne-sais-quoi», o «bel usage du monde» ${ }^{30}$ - têm um papel essencial. Existe, assim, um vínculo circunstanciado (de extensão e de ornamento) do espaço literário e do espaço social que determina uma fusão do «honnête homme» no "galant homme», sem que a "honnêteté» se afaste de uma cauçáo ética que, ainda assim, obsta à dimensão puramente estética e, portanto, efémera, da "galanterie».

Nesse sentido, a ambiguidade do conceito explica que Vaugelas, nas Remarques, tente ultrapassar as "choses extérieurs» que lhe estão subjacentes para se centralizar na ideia de "contrainte sans affection et sans vice» e para, no quadro de um purismo que lhe é particular (uma espécie de culto da interioridade linguística pela perfeição), justificar a vasta produção galante da época ${ }^{31}$ : de Alcippe ou le Choix des galants de Somaize (1661), La Fine Galanterie du temps de Faure (1661), as Euvres galantes de Cotin (1663), Les Entretiens galants de Donneau de Visé (1663), Les Récréations galantes de Sorel (1671), os Annales galantes de Mme de Villedieu (1671), aos romances de Mlle de Scudéry, Clélie e Le Grand Cyrus, entre outros.

honteuses et des honnestes habitudes»; «De la conversation des femmes - Description du cercle; Les Reynes et les Princesses; Les Dames; Les Filles d'Honneur; De la conversation du Louvre et de ses incommoditez; Du choix qu'il faut faire à la ville; Des menus preceptes; De la presence exterieure; Des habits; De la mode des habits et de leur assortissement; contre les inventeurs des modes extravagantes; De la probité des hommes; Menus preceptes» (Nicolas Faret, L'Honeste Homme ou L'Art de Plaire a la Court. Paris: chez Toussainct Quinet, 1636).

${ }^{28}$ Ver Bernard Beugnot, «Spécularités classiques», in Bernard Beugnot, op. cit., 1994, pp. 173-181.

${ }^{29}$ Para a análise do percurso das teorias de Faret às de Méré, ver, entre outros, Emmanuel Bury, «Le Monde de l'honnête homme: aspects de la notion de 'monde' dans l'esthétique du savoir-vivre», in Littératures Classiques ("La notion de "Monde» au XVIIe siècle»), no 22, 1994, pp. 191-202; Claude Chantalat, $A$ la recherche du goût classique. Paris: Klincksieck.Dens, 1992; Jean-Pierre, op. cit., 1981; Maurice Magendie, op. cit., 1970; Michael Moriarty, Taste \& Ideology in Seventeenth-Centuary France. Cambridge-New York-New Rochelle-MelbourneSydney: Cambridge University Press, 1988.

${ }^{30}$ Ver Jean-Pierre Dens, op. cit., 1981, pp. 56, 72.

${ }^{31}$ D. Denis assinala a importância das afirmaçōes desenvolvidas por Vaugelas nas Remarques a propósito da "galanterie» e da ambiguidade do conceito, citando o autor: "On demande ce que c'est qu'un homme galant, ou une femme galante de cette sorte, qui fait et qui dit les choses d'un air galant, et d'une façon galante. (...) D'autres disaient que ces choses extérieurs ne suffisoient pas, et que ce mont galant, avait bien une plus grande estendüe, dans laquelle il embrassait plusieurs qualitezs ensemble, qu'un un mot c'estoit un composé où il entroit du je ne sçay quoi, ou de la bonne grace, de l'air de la Cour, de l'esprit, du jugement, de la civilité, de la courtoisie et de la gayeté, le tout sans contrainte sans affectation, et sans vice. Avec cela il y a dequoy faire un honneste homme à la mode de la Cour» (Delphine Denis, op. cit., 2001, p. 100). Também Alain Viala discorre sobre a complexidade do conceito, ilustrando os seus argumentos com fontes diversas - Méré, Furetière, Vaugelas, etc (op. cit., 2008, pp. 31-36, 125-126). 
Neste contexto (e passamos a uma outra cenografia), os signos de exterioridade ou públicos do espaço mundano do «homme galant» sugerem uma evolução do «honnête homme» de Faret para o da «época clássica» francesa, pós-barroca mais ainda, julgo, ontologicamente barroca: o rosto agora ostentado, revelado de modo menos contido e mais superficial (no sentido de que dialoga directamente com a projecçáo para o exterior do ser social), apoia-se na arte de agradar ao outro pela conversaçáo - "alambic des lectures ${ }^{32}-\mathrm{e}$, por conseguinte, numa cultura retórica que amplifica a conversação peninsular e introduz, de novo, a dissonância na continuidade. De facto, La maison des Jeux de Charles Sorel (1642) e Les Jeux de Mlle de Scudéry (1667) descrevem uma assembleia de «honnêtes gens» que praticam os «jeux de conversation et de l'esprit», assente num imaginário alegórico (semelhante ao da Carte de Tendre) através do qual se exploram os percursos para atingir uma perfeição nos sentimentos e comportamentos que tenta apagar a dissolução de valores e a decadência da aristocracia denunciados por Alceste, o «misanthrope» de Molière. A desfiguração do rosto da Corte de Versailles é, em certa medida, compensada pela pluralidade e exuberância de rostos, pelo imaginário de uma palavra colectiva, artificial e ritualizada - uma "cenografia pública» ${ }^{33}$ - que compensa esse vazio ontológico e político. Tanto mais que essa palavra colectiva, que cria efeitos especulares evidentes entre Corte e Salóes literários e "précieux», privilegia o elemento feminino (uma outra máscara de sociabilidade pertinente no imaginário do século XVII francês), a ponto de os próprios textos (tratados ou romances) reflectirem um paralelismo de sexos que se vincula à essência antropológica do ideal da "honnêteté»: L 'honnête femme (1632-36) de Du Bosc, L'Honneste fille (1639-1640) e L'Honnête veuve (1640) de Grenaille, Egalité des hommes et des fermmes (1622) de Marie de Gournay, Les femmes illustres (1642) de Georges de Scudéry ${ }^{34}$. "L'empire des femmes ou l'esprit de joie», título de um importante capítulo da Diplomatie de l'esprit de Marc Fumaroli ${ }^{35}$, reflecte o poder que a mulher tem na definição da etiqueta e das formas da "politesse mondaine», apreendida, de modo acutilante, em 1675, pelo Abée de Villiers: "C'est la moindre chose que de plaire aux savants. Il faut plaire à la cour. Il faut être du gôut des dames pour réussir» ${ }^{36}$.

\footnotetext{
${ }^{32}$ A expressão "La conversation, alambic des lectures» é título de um capítulo da obra de J.-M. Chatelain dedicada à biblioteca do "honnête homme» e à intersecção da leitura com a conversação (Jean-Marc Chatelain, La bibliothèque de l'honnête homme. Livres, lectures et collections en France à l'âge classique. Paris, Bibliothèque Nationale de France, 2003, pp. 19-28). Ver, igualmente, a este propósito, La Conversation au XVIİme siècle. Actes du XII Colloque de Marseille. Marseille, C.M.R. 17 (Centre Méridional de Rencontres sur le XVIIe siècle), 1983.

${ }^{33}$ Delphine Denis, op. cit., 2001, p. 240.

34 Torna-se essencial para a contextualizaçáo dos conceitos de «honnête home» e "honnête femme» na cultura francesa do século XVII a consulta do capítulo que J. Mesnard consagra ao tema: "Honnête homme et honnête femme dans la culture du XVII siècle», in La Culture du XVIIe siècle - enquêtes et syntheses. Paris: PUF, 1992, pp. 142-159.

${ }^{35}$ Marc Fumaroli, La diplomatie de l'esprit. De Montaigne à La Fontaine. Paris: Hermann Éditeurs, 1994, pp. 321-339.

${ }^{36}$ Villiers, Entretiens sur les tragédies de ce temps. Paris: 1675, p. 59 (ver comentários à citação em John Lough, Writer and public in France. From the middle ages to the present day. Oxford: Clarendon Press, 1978, pp. 144-145).
} 
Sempre voltado para a exteriorização de emoçôes, para a "grâce naturelle», «l'empire des femmes» é também, por conseguinte, a marca justa de mais uma dissonância que se impóe entre o "honnête homme» e o «discreto», mesmo que o autor associe essa "civilisation du loisir» ${ }^{37}$ à filosofia de Santo Agostinho e, por conseguinte, nos deixe na incerteza (que é também epocal) entre a espiritualidade e a salvação que percorrem a educaçáo da aristocrata e a superação desse domínio ascético pela dissimulação, ou antes, pela simulação cortesã e pela utilização estratégica da palavra. No espaço peninsular, a "descortesia de algũas palavras» ${ }^{38}$ convocada em $A$ Visita das Fontes da qual decorre uma reflexão sobre a discrição ou indiscrição de alguns gramáticos, certas alusóes a regras da conversação, circunscrevem esse poder retórico a uma sociedade cortesã restrita, descrita pela Fonte Velha e por Apolo, a personagem legitimada pelo autor, no quadro da alegoria, para discorrer sobre a galanteria e as formas de tratamento no universo cortesão ${ }^{39}$. Ainda que se possa intuir uma alusão velada à mulher, por parte de Apolo, ela é confinada à denegaçáo (o que deve ser proibido no âmbito da prudência cortesã) e, portanto, a um fechamento social coincidente com a aura de melancolia que domina o presente onde a galantaria está «muito sincopada» ${ }^{40}$.

O mesmo é dizer que a mulher "discreta» - aquela a que se alude de forma esquiva na Carta de Guia de Casados - não apresenta propriamente uma função dramática no enquadramento peninsular, fechando-se no círculo de uma moralidade que a própria sociedade lhe incute: «Fale a mulher discreta o necessário, brando, a tempo, com tom que baste para ser ouvida da pessoa a quem fala e não das outras» ${ }^{41}$. A própria palavra encontra-se, assim, confinada à interioridade - uma espécie de discurso de ocultaçáo cujo sentido se constitui pela mediação calculada da honra e da prudência. A conversação "discreta» parte, deste modo, de um paradigma retórico, social e político diferente do da conversação galante: a matriz da ilusão está presente nos dois casos mas a sua representação é diversa. A primeira, como mostram Gracián ou D. Francisco Manuel, movimenta-se na virtude da prudência, numa ilusáo controlada ética e esteticamente; a segunda oscila entre o interior dos laços sociais e um ritual colectivo - o das «honnêtes gents galantes» que vêm no

${ }^{37}$ "On voit ainsi s"établir, en marge de la Cour et de la vie publique, une civilisation du loisir, enchantée par la parole, par ses jeux d'esprit, depuis les plus futiles jusqu'aux plus ambitieux, et par les jeux des lettres, depuis les petits genres galants jusqu'au théâtre et naturellement à l'églogue, genre si approprié à cet univers désamarré de la réalité pratique et bourgeoise» (Marc Fumaroli, op. cit., 1994, p. 338).

${ }^{38}$ D. Francisco Manuel de Melo, op. cit., 1998, p. 43.

39 "[Apolo] A três pontos se reduz hoje a galantaria, ou já lhe chamemos tempos, partes, ocasiōes. O primeiro é: lugares públicos diante dos Reis; o segundo: lados de passeo; o terceiro: cabeças de motes (...) Os lugares públicos se alcançam nesta maneira, ũa vez declarado o galante por servidor de ũa Dama, sendo chegada algũa a ocasião de lugares (...) manda pedir lugar o galante a aquela Dama; e ela se serve de admiti-lo, o comunica à Camareira-mor da Rainha, que com sua permissão lho concede. Há contudo aqui ũa treta: que de ordinário se não faz este favor na maneira em que se pede, mas quando o lugar é pretendido para com a tal Dama, se concede para com outra sua amiga; e desta sorte se repartem e assinam os lugares, sucedendo que a $\sim$ ua só Dama pelo menos lhe acomodam dous galantes: o que também se faz com artificio» (ibidem, p. 122).

${ }^{40}$ Ibidem, p. 120.

${ }^{41}$ D. Francisco Manuel de Melo, op. cit., 1996, p. 139. 
«agrément de l'esprit et du discours» uma forma de dar continuidade ao ideal de Faret, uma vez concebida a dissimulaçáo como virtude honesta para a aristocrata em decadência da segunda metade do século XVII ${ }^{42}$.

Assim, impossibilidade antropológica de o "honnête homme» se desvincular, ao longo do século, sob diversas figuraçóes, do universo exterior, desse universo repleto de olhares que se auto-reflectem (no campo social, no campo literário), faz-se, também, pela contemplação desse mundo exterior como um espaço de teatralidade onde o «bonheur social» se conquista pela entrega a um papel, à dramatização de comportamentos, que tendem a espelhar o equilíbrio ou a modéstia interiores, sem que o homem se possa confinar, como o "desenganado» peninsular, a esse isolamento do ser (o insucesso de Alceste no Salão de Célimène, em Le Misanthrope mostra essa impossibilidade ideológica e decorre, em parte, do processo desajustado da misantropia que Molière, homem do "Grand Siècle», denuncia sob uma ironia velada e com a melancolia radiosa de um précieux). Daí que o «éclat» mundano dos Salóes, dos longos romances barrocos da primeira metade do século (de D’Urfé, Scudéry, Gomberville), onde as paixóes de cortesãos disfarçados de pastores ou de príncipes que se refugiam em não-lugares como as Arcádias, se depuram e se tornam artificiais, ou, ainda o "éclat» das novelas galantes dos anos 60 a 80, em que o ideal neoplatónico é substituído pelo mundano, constituam, em diferentes graus, uma outra dissonância ontológica e estética, contígua às anteriores, relativamente ao universo muitas vezes desenganado do «discreto».

A história individual do «discreto» obedece, com efeito, no quadro peninsular, a um jogo dialéctico de alguma complexidade que faz interferir padróes de dissimulação virtuosa na consciência trágica de que a imagem desenganada do mundo se actualiza na Corte dissimulada, distante da antiga modéstia portuguesa (que Rodrigues Lobo preserva, com insistência, na Côrte na Aldeia) e que, como observa Maria de Lurdes Correia Fernandes, em síntese introdutória à sua edição da Carta, se inscreve no pessimismo antropológico que marcou o período barroco na Península ${ }^{43}$. Essa «farsa em que todos andam» ${ }^{44}$ denunciada pelo Relógio da Cidade, a insistência, topicamente contextualizada e a que o Autor não se pode furtar, apesar da sua aura cosmopolita, nas virtudes do campo por oposição aos vícios do mundo enunciados no diálogo final entre os Relógio da Cidade e o da Aldeia, a visão do pecador e da morte ${ }^{45}$, a «sepultura» e a «Roda» da Fortuna que os

${ }^{42}$ Christoph Strosetzki, Rhétorique de la conversation - sa dimension littéraire et linguistique dans la société française du XVIIe siècle. Paris-Seattle-Tübingen: Biblio 17 (PFSCL), 1984.

${ }^{43}$ Maria de Lurdes Correia Fernandes, "Introdução», in Melo, D. Francisco Manuel de, Carta de Guia de Casados. Porto: Campo das Letras, 2003, p. 30.

${ }^{44}$ D. Francisco Manuel de Melo, op. cit., 1998, pp. 20-21.

45 «[Relógio da Cidade:] O Tempo é touro bravo e em tomando nos cornos um pecador, se por si mesmo se não faz morto, o mesmo touro o mata.»; "[Relógio da Cidade:] Vem entáo a velhice, a [melancolia] e o quebranto, de que procede o aborrecimento de todas essas cousas que se prezaram, e faz como os homens se despeçam da vida não só com conformidade mas, algũa vez, com alvoroço. Donde se viu que muitos sábios requestaram a hora da morte, e alguns da gentilidade barbaramente a anteciparam, por se verem livres das penalidades da vida" (ibidem, pp. 21, 24). 
dois Relógios evocam como processo final de decadência e de irreversibilidade temporal ${ }^{46}$, o pessimismo agustiniano das personagens autorais de Quevedo e Lípsio no Hospital das Letras, são a face alegórica da relação polémica que o «discreto» desenvolve com a sociedade aúlica e da oscilação permanente, que marca o seu comportamento, entre invisibilidade e visibilidade contida. Nas máscaras do homem político - reis e príncipes - cabe, assim, a do "desenganado», vinculada a uma simbólica das "Pasiones Frias» como estratégia melancólica ${ }^{47}$, sendo estas signos, ora da agudeza prudencial do cortesão construída por Gracián (para quem «a melancolia foi sempre manjar de discretos» ${ }^{48}$ ), ora da própria imagem cosmopolita de D. Francisco Manuel, homem de cortes plurais que compreende, através das suas personagens alegóricas, das suas personagens de e do artifício, a esfera solitária que envolve o "discreto», distante da esfera do brilho colectivo que envolve o «honnête homme».

Ainda assim, esta dissonância antropológica fundamental - o desengano não é (apenas) o "désenchantement» - tem como ponto comum aos dois paradigmas comportamentais a ilusão, esse princípio de sobrevivência modal do Barroco nos contextos peninsulares e francês (a derradeira e brevíssima hipótese teórica deste confronto). A crise de representação sobre a qual assenta a relação do «discreto» e do "honnête homme» com o mundo - num primeiro caso submersa numa dissimulação controlada; no segundo caso, expressa por uma simulaçáo exibida - apresenta, de acordo com o estigma múltiplo da ostentação e da melancolia barrocas, uma tendência para a ficcionalização das emoçóes e dos gestos que se espelha, em meu entender, na forma alegórica (no espaço peninsular) e na forma romanesca, pela via da alegoria (no espaço francês), com que se instituem essas figuras em personagens ${ }^{49}$. A ficção como marca indelével da arte do distanciamento permite fazer a hermenêutica dos dois modelos, sugerindo, num exercício de metapoética, o cruzamento de tratados didáctico-morais, panfletos políticos, textos historiográficos com textos alegóricos (como os Apólogos) ou com textos romanescos (como os romances sentimentais de Mlle de Scudéry ou o romance pastoril de Honoré d'Urfé, significativo manual de «civilité» e de «savoir-vivre» ${ }^{50}$ ).

\footnotetext{
46 "[Relógio da Cidade:] Estai seguro de que não há neste mundo cousa tão abatida que algũa hora se não veja levantada. A Roda que se lhe pinta à Fortuna deve ser de engenho de nora, donde os homens sáo alcatruzes: uns cheos, outros vazios, uns no fundo, outros no alto" (ibidem, p. 23).

${ }^{47}$ A posição aqui assumida sobre o «desenganado» decorre de um entendimento deste estado tal como Rodriguez de la Flor o desenvolve no âmbito das "pasiones frias" barrocas, como forma dos labirintos do «eu", modo de operar a dissolução do espelho terrestre (Rodriguez de la Flor, F., op. cit., 2005, p. 90).

${ }^{48}$ Ver citação contextualizada em ibidem, p. 36.

${ }^{49}$ Ver E. Bury, «Civiliser la 'personne' ou instituer le 'personnage'? Les deux versants de la politesse selon les théoriciens français du XVIIe siècle», in Montandon, Alain (dir.), Étiquette et politesse. Clermont-Ferrand: Coll. Littératures, 1992, pp. 125-138.

${ }^{50}$ Ver, a este propósito, Delphine Denis (dir.), Lire L'Astrée. Paris: Presses Universitaires de la Sorbonne, 2008; Marc Fumaroli, «Le retour d'Astrée», in Jean Mesnard (dir.), Précis de Littérature Française du XVII siècle. Paris: PUF, 1990, pp. 47-64; Eglal Henein, Protée romancier. Les déguisements dans "L'Astrée» d'Honoré d'Urfé. Fasano-Paris: Schena-Nizet, 1996; Françoise Lavocat, Arcadies Malheureuses. Aux origines du roman modern. Paris: Champion, 1998; Maurice Magendie, Le roman français au XVII siècle. De "L'Astrée» au «Grand Cyrus.
} 
Entre o diálogo de imaginação anunciado no Prólogo de Os Relógios Falantes ${ }^{51}$, os exercícios poéticos e o trabalho da memória dos autores-personagens (o Autor, Quevedo, Lípsio) no Hospital das Letras, responsáveis pela concepção e pela avaliação das «letras» de discretos sobre discretos, observa-se um modo de instituir a ética do conceito pela artificialidade material da sua escrita - uma espécie de solução metafísica ou poética de fazer significar essa relação do homem com o espaço aúlico que não trai a teatralidade da sociedade e da cultura peninsulares. Do mesmo modo, entre a cartografia alegórica que, no Grand Cyrus de Mlle de Scudéry, conduz príncipes e cortesãos do «lac d'indifférence» ao palácio da "honnête amitié», ao modelo romanesco que opta muitas vezes pela inventio da "clé», do «nom supposé», estabelecendo uma relação entre a personagem de ficção e o aristocrata de Salão, pressupóe-se uma aprendizagem da «art de vivre à la cour» manifestamente enraizada num pacto escritural galante e numa "fabricação» (estética) do texto associada ao imaginário da palavra colectiva que é a "conversation honnête». Nos dois contextos, porém, a ficção (alegórica e/ou romanesca) reforça a emergência de dois modelos que se deslocam com prudência (aqui em duplo sentido), da ética para a estética, no imaginário labiríntico peninsular e francês da época barroca. $\mathrm{O}$ último cenário de $A$ Visita das Fontes acentua o segredo como forma de preservar a virtude, a «discriçáo», a "prudência» (que são formas de dissimulação): "vós filha [diz a Fonte Velha à Fonte Nova], guardai segredo a tudo o que ouvistes»; «Faço-me muda» responde a Fonte Nova; «Torno-me pedra» conclui Apolos ${ }^{52}$.

Nos Apólogos, o diálogo alegórico fecha-se sobre a própria alegoria. Em L’Astrée, o desenlace, espaço completamente artificial onde os cortesáos disfarçados de pastores atingem o «honnête repôs» (o clímax da aprendizagem aúlica) pela reposição das suas identidades ficcionais, deixa antever o fechamento da ficção sobre a ficção. As duas cenografias - alegórica e romanesca - serão, assim, eventualmente, a síntese dos outros lugares cénicos evocados, a forma de significação, isto é, de representação mais promissora do diálogo dissonante entre "discrição» e «honnêteté».

Paris: Librairie E. Droz, 1932; Kathleen Wine, "L'Astrée's landscapes and the poetics of Baroque fiction", in Symposium, pp. 141-153.

${ }^{51}$ «O primeiro fim com que escrevi este apólogo foi só por divertir-me dos penosos cuidados que há tantos anos me acompanham, ou por melhor dizer, me perseguem» (D. Francisco Manuel de Melo, op. cit., 1998, p. 4).

${ }^{52}$ D. Francisco Manuel de Melo, op. cit., 1998, p. 127. 
Série

Documentos

Imprensa da Universidade de Coimbra

Coimbra University Press

2010

- U

C • 